
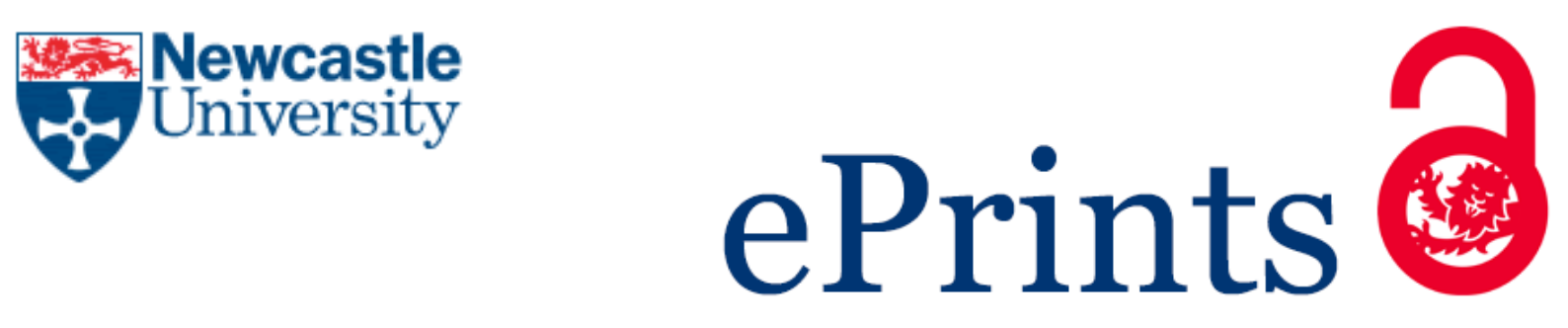

Ogie RI, Holderness T, Dunn S, Turpin E.

Assessing the vulnerability of hydrological infrastructure to flood damage in coastal cities of developing nations. Computers, Environment and Urban Systems 2017, 68, 97-109

Copyright:

(C) 2017. This manuscript version is made available under the CC-BY-NC-ND 4.0 license

DOI link to article:

https://doi.org/10.1016/j.compenvurbsys.2017.11.004

Date deposited:

$07 / 02 / 2018$

Embargo release date:

21 May 2019

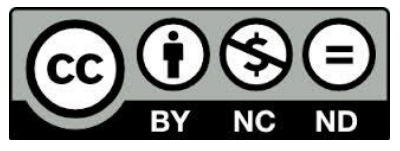

This work is licensed under a

Creative Commons Attribution-NonCommercial-NoDerivatives 4.0 International licence 


\title{
Assessing the vulnerability of hydrological infrastructure to flood damage in coastal cities of developing nations
}

\author{
R. Ogie ${ }^{1}$, T. Holderness ${ }^{2}$, S. Dunn ${ }^{3}$, E. Turpin ${ }^{2}$ \\ ${ }^{1}$ Smart Infrastructure Facility, University of Wollongong, Northfields Ave, Wollongong, New South Wales 2522, \\ Australia \\ ${ }^{2}$ The Urban Risk Lab, Massachusetts Institute of Technology, Cambridge, MA 02139, USA \\ ${ }^{3}$ School of Civil Engineering \& Geosciences, Newcastle University, Newcastle, Tyne and Wear NE1 7RU, UK
}

\begin{abstract}
Hydrological infrastructure such as pumps, floodgates (or sluice gates), dams, embankments, and flood barriers are invaluable assets used for controlling water in flood-prone areas such coastal cities. These infrastructure components are often vulnerable to damage or failure due to the impact of floodwaters, thus leaving people and urban property exposed to flood hazards. To minimise the failure of hydrological infrastructure during intense flooding events, it is important to identify the most vulnerable components and to invest scarce resources in reducing their vulnerability. Using the concepts of exposure, susceptibility and resilience, this study proposes a graph-based network approach for measuring the vulnerability of hydrological infrastructure to flood damage in coastal cities. In this graph-based approach, hydrological infrastructure are represented as network nodes and the waterways as edges. The proposed vulnerability assessment approach is applied to measure and rank the vulnerability of floodgates in one of the most exemplary coastal cities - Jakarta, Indonesia. The results show that the proposed solution is both useful in highlighting the most vulnerable infrastructure components and also providing clues as to what actions can be taken to minimise infrastructure vulnerability. More so, the solution was found to be useful in identifying potential locations within the city of Jakarta, where additional infrastructure are required to improve resilience to flooding. This type of information about infrastructure vulnerability and resilience actions is vital to decision-making authorities responsible for planning, flood preparedness and prioritybased allocation of resources for the maintenance of flood control infrastructure in coastal cities.
\end{abstract}

Keywords: vulnerability, flood, network, coastal cities, floodgate, infrastructure

\section{Introduction}

Flooding in coastal areas is a frequently occurring problem that must be properly managed to minimise damage to urban property and loss of human lives (Al-Sabhan et al., 2003). Floods account for approximately $40 \%$ of all natural disasters and affect 20-300 million people every year (Dewan, 2013). It is predicted that the annual global 
flood losses will hit \$1 trillion in 2050 if drastic actions are not taken now (Hallegatte et al., 2013). Coastal cities, particularly those situated in the developing nations of Asia are expected to suffer a higher proportion of these flood losses because of the rapid processes of population growth, urbanisation, and land subsidence that increase their exposure to flood damages (Dewan, 2013; Dewan and Yamaguchi, 2008). Coastal cities in developing nations are therefore faced with a greater need to mitigate potential damage caused by fluvial and coastal inundations.

A common flood control strategy involves structural measures or the use of hydrological infrastructure assets such as pumping stations and floodgates (Hung et al., 2009; Ogie et al., 2017a). Generally, pumping stations are used to remove accumulating floodwaters from low-lying areas where gravity-fed drainage is not possible (Hardoy and Pandiella, 2009; Tingsanchali, 2012). Floodgates are used to control the flow of water by either keeping them closed or opened, depending on potential flood threats (Sims, 2013). Under normal drainage conditions, the floodgates operate by remaining open. However, as rainfall intensifies and storm surge builds, the floodgates are closed to prevent rising waters from flowing through and flooding dry lands and populated areas located downstream (Sims, 2013).

One major issue with floodgates is that they require regular maintenance during the monsoon season, without which they may fail to operate properly when needed to defend the coastal community against severe flooding events. The need for regular maintenance stems from the fact that floodgates are vulnerable to damages caused by large impact forces from floodwaters (Ke, 2014). The likelihood of damage is particularly higher in cases where aging and inadequate maintenance have resulted in infrastructure fragility (Turpin et al., 2013). For instance, aged and poorly maintained floodgates may experience damage to wheels, lower bumpers, and other hydraulic components as a result of high velocity flows and debris impact (Grega et al., 2010). Gates may get stuck or fail to close fully when debris are wedged between the wheels or deposited under the gates (Grega et al., 2010). Regular maintenance is therefore required to ensure the floodgates are operable, particularly during the monsoon season (Caljouw et al., 2005).

However, in coastal cities situated in developing nations, the shortage of funding and available resources limit the scope and frequency of maintenance of the hydrological infrastructure (Lall and Deichmann, 2012). The failure of poorly maintained hydrological infrastructure has been reported as a major cause of flooding in coastal cities 
situated in developing nations (Hardoy and Pandiella, 2009; Lall and Deichmann, 2012). Examples of cities that often experience flooding as a result of the failure of flood control infrastructure include Manilla, Jakarta, Mumbai, Dhaka, Tokyo, and Shanghai, to name a few (Dewan et al., 2007; Ke, 2014; Mulyasari et al., 2011; Stalenberg and Vrijling, 2009; Uitto, 1998). Critically, in cities which are dependent on flood control infrastructure, fluvial and coastal inundation may be caused or exacerbated by the failure of one or more infrastructure components, potentially resulting in significant damage to urban property and loss of human lives (Dawson et al., 2008). It is therefore crucial that the limited resources available for maintenance and upgrade of the hydrological infrastructure be judiciously allocated in a manner that improves resilience and minimises failure during extreme flooding events (Sadoff et al., 2013). Ideally, such resource allocations should be effectively targeted at the most vulnerable components in the hydrological infrastructure network, and thus by spending scarce resources on the most vulnerable components in the flood control network, infrastructure failure resulting in flooding can be minimised (Hall et al., 2003).

A quantitative assessment of vulnerability can aid decision makers in identifying the most vulnerable components within a system, which should be prioritised for preventative actions (Balica et al., 2012). The concept of vulnerability assessment has been widely discussed in the literature, particularly as it relates to people and community (e.g., Chakraborty and Armstrong, 1995; Dewan 2013; Ciurean et al., 2013; Green, 2004; Huang et al., 2012; Jenelius and Mattsson, 2015; Khan, 2012; Masuya et al., 2015). However, physical infrastructure assets that are crucial to the safety and day-to-day operation of modern society are also vulnerable to damage associated with natural hazards (Kawamura et al., 2014). Hence, similar assessments that focus on the vulnerability of different types of infrastructure networks to natural hazards have received significant attention in the research community (Johnston et al. 2014; Tonmoy and El-Zein, 2013; Wei et al., 2015). For example, using the geographical layout of graph models and polynomial-time algorithms, Neumayer et al. (2011) show how to highlight the areas in a fiber-optic communication infrastructure network that are most vulnerable to natural disasters in terms of maximum disruption to capacity and connectivity. Ezell (2007) proposed Infrastructure Vulnerability Assessment Model (I-VAM) based on the mathematics of multi-attribute value theory and show how the vulnerability for each component in a clean water supply network can be quantified by using the protection measures of deterrence, detection, delay, and response. Other infrastructure systems that have benefited from vulnerability assessments to natural hazards include road transport (Taylor et al., 2006), aviation (Wilkinson et al., 2012), and electric power (Holmgren, 2006) networks. However, no standardised processes yet exist for 
quantitatively assessing and ranking the vulnerability of hydrological infrastructure components to damages caused by floodwaters. The lack of a standardised process of finding suitable metrics combined with the data scarcity in developing countries complicate this task (Balica et al., 2012; Brecht et al., 2012).

Motivated by this problem, this study proposes a graph-based network approach for measuring and ranking the vulnerability of hydrological infrastructure components to damage caused by the impact of floodwaters. The graph-based network utilised in this study is a directional graph (digraph) in topological vector format, showing how elements of the hydrological infrastructure network are connected within the city. Graph theory is considered appropriate for this problem because it provides a rigorous mathematical basis for computing vulnerability (Dunn and Wilkinson, 2012; Dunn et al., 2013), using very little data obtainable at the time and allowing for further improvement from the initial results as additional data becomes available in the future (Bunn et al., 2000). In exploring this technique, a general equation for computing the vulnerability of floodgate to floodwater damage is first established, based on the concepts of exposure, susceptibility and resilience. Using the derived equation, a case study implementation is then carried out to assess and rank the floodgates in the city of Jakarta, Indonesia, according to their vulnerability to damage caused by floodwaters.

In applying the derived equation to Jakarta's case study, suitable metrics are systematically derived using a constructed spatio-topological network model of the city's hydrological infrastructure system. The results of the application are Hydrological Infrastructure Flood Vulnerability Index (HIFVI) values representing the degree to which each floodgate in the city of Jakarta is vulnerable to damage caused by the impacts of floodwaters. The computed HIFVI values are stored in a spatial database table and accessible for visualisation using geographical information system software. Such detailed analysis results are useful to decision makers in coastal communities when planning and prioritising infrastructure maintenance and resource allocation for flood preparedness (Odeh, 2002). The remainder of this paper is organised as follows: In the next section the process followed to derive the equation for computing HIFVI is presented. Section 3 presents a case study application to Jakarta's floodgate infrastructure. In section 4, the results are presented and their implications discussed. Finally, section 5 concludes the paper, presents major limitations, and makes suggestion for future studies.

\section{Equation derivation for computing hydrological infrastructure flood vulnerability index}


The study of vulnerability to natural hazards is a burgeoning research area that cuts across several fields of study including health, social science, psychology, policy development, climate science, economics, disaster management, engineering, etc. (Brooks, 2003). This multidisciplinary nature of vulnerability research has resulted in fragmentation in the conceptualisation of vulnerability and indeed, the methodological approaches for assessing it (Brooks, 2003; Dewan, 2013). There is, in fact, no universally accepted definition for the term, vulnerability and attempts to provide a unified framework are often constrained by numerous conceptual linkages to an array of terms such as resilience, risk, sensitivity, and adaptive capacity, most of which are also conceptualised differently in the literature (Cutter et al., 2008; Dewan, 2013). A summary of definitions and the various conceptual frameworks and methodological approaches related to vulnerability assessment are too extensive to be covered in this article without detracting from the focus. A number of studies, with strong focus on reconciling definitions and conceptual linkages within vulnerability research, have already contributed significantly in this regard and the authors would like to refer interested readers to a few of them (Adger, 1999; Cutter et al., 2009; Brooks, 2003; Dewan, 2013).

Nevertheless, an important point to emphasis is that vulnerability is only meaningful when it is discussed in relation to a "specified hazard or range of hazards" affecting a "specified system" (Brooks, 2003, p.3). In the literature, it is common to find discussion of vulnerability assessment in relation to a specified hazard affecting people and community. Vulnerability assessment at a community scale is a broad exercise and ideally, the definition of key indicators should consider elements from the physical environment (e.g., proximity to hazards, elevation, geomorphic features, land use practice, etc.) as well as the social dimensions (e.g., demographics, population, poverty, marginalisation, inequality, etc.) (Dewan, 2013). In the present study, the focus is narrower as the specified hazard for which vulnerability assessment is being discussed is the damaging impact of flood water affecting a specified system- flood control infrastructure such as floodgates or sluice gates. In other words, the direct object assessed for vulnerability to flood damage is not people or community, but physical flood control assets, which by themselves have little or no social attributes (e.g., poverty, marginalisation, inequality) that directly define their vulnerability. In a sense, it is notable that the outcome of this type of vulnerability assessment, focusing on specific critical infrastructure assets within the urban environment, has social and economic implications for the people and communities they serve. However, such assessments and outcomes should not be viewed from the perspective of assessing the vulnerability of people or communities. This has implication for how we choose the methodology and indicators used for assessing the vulnerability of physical infrastructure as 
compared to people or communities. It is also important to note that the methodological approach and range of indicators used for vulnerability assessment depend on data availability (Dewan, 2013). In developing nations, where the required data is often not available, there is a constraint on methodological approaches and range of indicators that can be used for conducting vulnerability assessment (Dewan, 2013).

In the present study, vulnerability is defined as the degree to which a system is susceptible to and unable to recover from a hazardous condition (Thakur et al., 2012). Vulnerability can be derived based on three main factors: exposure, susceptibility (or sensitivity), and resilience (Balica et al., 2012). This can be represented mathematically using the general flood vulnerability index (FVI) formula (Eq. 1) (Balica et al., 2012).

$F V I=\frac{E * S}{R}$

Exposure is a precondition for a hazardous situation, in the absence of which an object cannot be said to be vulnerable (Hufschmidt, 2011). More specifically, exposure denotes the degree to which a system is in contact with or subject to perturbation or hazards (Gallopín, 2006). With regard to flood hazards, hydrological infrastructure components such as floodgates are exposed to the large impact forces from floodwaters in all river reaches that flow from upstream to the given floodgates (Ding and Wang, 2012). In the context of this study, the exposure of a given floodgate is determined by the length of all waterways that flow from upstream locations towards it, weighted by channel classification. In this classification adopted from Ogie et al. (2017b), channels with higher flow rates are given greater weighting as follows: $550 \mathrm{~m} 3 / \mathrm{s}$ and more $=1$, less than $550 \mathrm{~m} 3 / \mathrm{s}$ and more than $100 \mathrm{~m} 3 / \mathrm{s}=0.5$, less than $100 \mathrm{~m} 3 / \mathrm{s}=0.33$, and all other smaller watercourses and ditches $=0.25$. The channel classification as previously proposed by Ogie et al. (2017b) derives from an empirical observation of water flow in the hydrological network. Given that the number of waterways that flow from upstream locations towards a given floodgate can range from 1 to $n$, the product of the length, $l_{i}$, and weighting, $w_{i}$, for each of these waterways, $i$, can be summed to determine the exposure, $E$, of the floodgate. Mathematically, this can be represented as shown in Eq. 2.

$E=\sum_{i=1}^{n}\left(l_{i} * w_{i}\right)$ 
Susceptibility is a system characteristic, which determines the degree to which the system is affected by hazard (Balica et al., 2012). In order words, it is that aspect of the system that influences the probability of being affected by flood hazards. For instance, during intense flood events, a floodgate with lower capacity is considered more susceptible to failure or breakdown as compared to one with a greater capacity. Hence, given that $C_{g}$ is the capacity of a given floodgate, susceptibility, $S$ would decrease as $C_{g}$ increases. This relationship can be represented mathematically as shown in Eq. 3.

$S=\frac{1}{C_{g}}$

Resilience can be defined as the ability to absorb a shock and still maintain form or state without significant disruption or damage (Cutter et al., 2008). Resilience is a key element of vulnerability that denotes the persistence of systems (Cutter et al., 2008). All things being equal, a resilient system is considered less vulnerable to disasters than a non-resilient one (Gallopín, 2006). Resilience has properties with various dimensions, which makes it unclear what actually leads to resilience or what variables should be utilized to measure it (Cutter et al., 2008). The properties of resilience, sometimes referred to as the "4R's of resilience", include robustness (the strength or ability to withstand a given level of stress or load without suffering degradation or loss of function), redundancy (the availability of substitutable components that can be activated when a disaster occurs), resourcefulness (the capacity to mobilise material and human resources in response to a disaster), and rapidity (the capacity to function in an agile and timely manner in order to minimise losses and prevent reoccurrence of disaster in the future) (Chang and Shinozuka, 2004). Due to this multidimensional nature of resilience, a broad model that includes all four properties of resilience is yet to be empirically tested (Cutter et al., 2008). It is rather common to measure resilience based on one or more of these properties, subject to the availability of data (D'Lima and Medda, 2015; Venkittaraman and Banerjee, 2014).

In this study, resilience is derived as a function of redundancy (Chang and Shinozuka, 2004). The resilience of a given floodgate, $F G$, in the hydrological infrastructure network is determined based on redundancy provided by connected upstream floodgates (Chang and Shinozuka, 2004). Factors considered in measuring the redundancy provided by each connected upstream floodgate include capacity, $c$, geometric length, $g$ (i.e., distance along flow path(s) to $F G$ ), and the upstream network configuration. The connected upstream floodgates with higher value of $c$ and lower value of $g$ contribute more to the resilience of $F G$. Figure 1 provides a simple illustration to aid the understanding of how this works. In terms of upstream network configuration, a connected upstream floodgate 
would contribute maximally to the resilience of $F G$ if its location in the network allows it to divert floodwater from all the different channels flowing to $F G$ (as in the case of the resilience provided by $F G 1$ to $F G$ in Figure 1a.). However, with additional number of channels, $e$, connecting the link between the two floodgates (as in Figure 1b.), the contribution of the upstream floodgate, $F G 1$ to the resilience of $F G$ reduces accordingly. Hence, given that $F G$ has $m$ number of connected upstream floodgates, its total resilience, $R$ can be estimated using Eq. 4 .

$R=R_{m}+\sum_{i=0}^{m} \frac{c_{i}}{g_{i} * e_{i}}$

$R_{m}$ is the material resilience of the referent floodgate based on the physical property of its material, $\sum_{i=0}^{m} \frac{c_{i}}{g_{i} * e_{i}}$ is the total resilience contributed by the connected upstream floodgates, where $i$ is an element in the set of connected upstream floodgates, which may be made up of 0 to $m$ members. 0 member means that there are no connected upstream floodgates, in which case $\sum_{i=0}^{m} \frac{c_{i}}{g_{i} * e_{i}}=0$ and $R=R_{m}$.

It is important to note that in the absence of any defined measures of computing the material resilience of hydrological infrastructure, $R_{m}$ can be assumed a constant value of 1 for all floodgates in the network. This approach ensures that in the condition that $\mathrm{n}$ is 1 and redundancy is $0, \mathrm{R}$ will still have a non-zero value of 1 . By substituting Eq. 2, 3, and 4 into Eq. 1, a general equation (Eq. 5) is obtained for estimating FVI (i.e., HIFVI) in the context of hydrological infrastructure for flood control, specifically floodgate.

$H I F V I=\frac{\sum_{i=1}^{n}\left(l_{i} * w_{i}\right)}{c_{g}\left(R_{m}+\sum_{i=0}^{m} \frac{c_{i}}{g_{i} * e_{i}}\right)}$

Eq. 5 is considered ideal for computing HIFVI under normal flow conditions, assuming that one or more connected upstream floodgates may be closed during the flood control process, thereby easing the impact of floodwaters on the downstream floodgate. However, there is possibility of a worse-case scenario i.e., case in which all upstream floodgates are opened so that water flows unobstructed to the downstream floodgate, creating maximum impact. This condition gives rise to $\operatorname{HIVI}_{(\max )}$ as shown in Eq. 6. In mathematical terms, this implies $\sum_{i=0}^{m} \frac{c_{i}}{g_{i} * e_{i}}=0$ as there is no resilience based on redundancy provided by connected upstream floodgates.

$\operatorname{HIFVI}_{(\max )}=\frac{\sum_{i=1}^{n}\left(l_{i} * w_{i}\right)}{C_{g} * R_{m}}$ 
While Eq. 5 may apply specifically to floodgates or sluice gates, Eq. 6 can be applied in computing flood vulnerability index for a wider range of hydrological infrastructure, including floodgates, sluice gates, dams, flood walls, embankments, dykes, and other flood barriers.

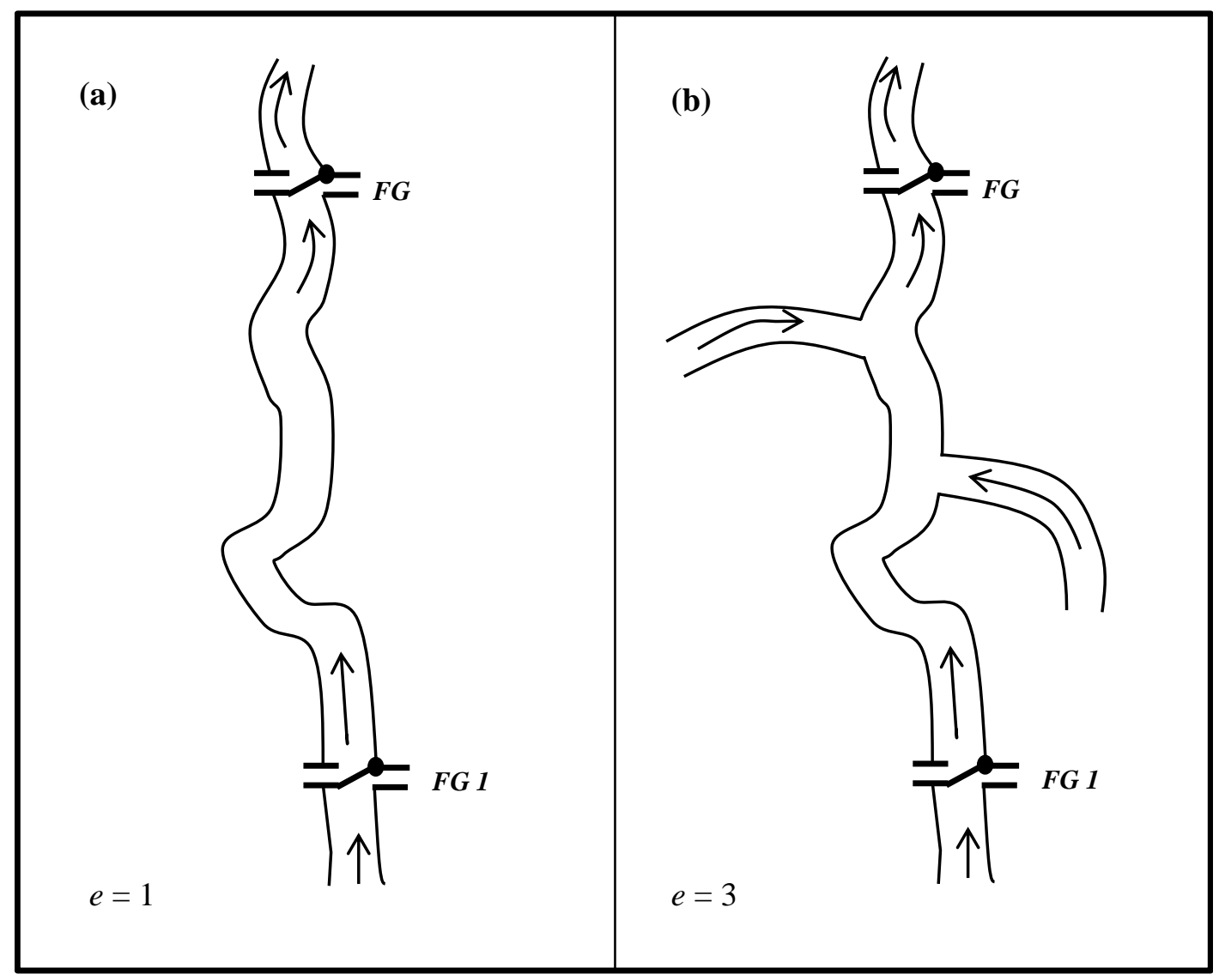

Figure 1. Illustration of how upstream network configuration affects resilience

\section{A case study application to compute the vulnerability of Jakarta's hydrological infrastructure}

The city of Jakarta, Indonesia was chosen for this study because it is one of the most representative coastal cities of developing nations that depend heavily on structural measures or hydrological infrastructure such as floodgates to mitigate flood risks ( $\mathrm{Li}, 2003)$. As a low-lying delta city served by thirteen naturally occurring rivers and hundreds of man-made drainage canals (World Bank, 2010), Jakarta relies on a network of floodgates to control water flowing from surrounding hills and mountains, through the city to the Java Sea (Hartono et al., 2010). The consistent use of these ageing and poorly maintained hydrological infrastructure components during the annual monsoonal flooding that occur between November and March exposes them to the damaging impacts of floodwaters, with frequent breakdown or failure as a consequence (Turpin et al., 2013). The failure of the hydrological infrastructure often result in severe flooding events that have devastating impact on the people, 
property, economy, and environment, with an estimated annual cost of more than USD 400 million (World Bank, 2010).

The Word Bank (2010) recommends that as a matter of utmost urgency, a good adaptation action for the city of Jakarta should quantitatively highlight areas of high vulnerability and focus limited resources on the maintenance and upgrade of existing hydrological infrastructure. In this study, the vulnerability of Jakarta's floodgate infrastructure to flood damage is quantitatively assessed using a graph-based network approach. The study involves the use of ground survey, GPS locations and aerial imagery analysis to capture and record the names and locations of the different floodgates and waterways in Jakarta. The resulting waterways vector data is of line geometry type while the floodgates vector data made up of 30 records is of point geometry type.

To reduce locational errors in the survey data, e.g. from aerial imagery tracing, a series of pre-processing steps were undertaken prior to analysis. The floodgates dataset contained a number of topological errors where points did not intersect line geometries in the mapped waterways data. This error was fixed by programmatically snapping point features to the nearest waterway and further validating the output using actual ground knowledge of the locations of flood control infrastructure in the waterways network. Similarly, the waterways dataset was considered to be topologically incorrect because of the presence of undershoots and overshoots arising from digitisation errors, potentially contributing to erroneous network analysis results such as in shortest distance computation (Ogie et al., 2017a). These errors were fixed using the topology toolset and GRASS plugin within the QGIS software. Furthermore, edges in the waterways data were programmatically split into separate line features where they self-intersected or intersected floodgate infrastructure. This is to create junctions that make the datasets suitable for network construction.

The construction of the graph-based spatio-topological network model of Jakarta's flood control infrastructure was carried out using the PostGIS spatial database schema and coupled Python interface to the NetworkX graph analysis package developed by Newcastle University (Barr et al., 2012). A spatio-topological representation enables the model to consider the spatial structure of the network as well as its topology (Ogie et al., 2017a). Topology was encoded within the data using a system of unique node and edge primary keys. Owing to the absence of high resolution and accurate elevation data for Jakarta, flow direction was inferred by edge orientation assuming the general condition of water flowing from the mountains of Bogor to the south of Jakarta, and through 
the city to the Java Sea in the north. Subsequent corrective adjustments to flow direction were then made based on actual field observations of water flow in the city of Jakarta. The resulting constructed network is a multidigraph comprising 628 edges representing Jakarta's rivers and drainage channels, with a total geometric length of $1092 \mathrm{~km}$. The network also comprised 520 nodes, with 30 of them representing actual floodgate infrastructure, and the remainder being network junctions such as river confluences. The rationale for modelling the network as a multidigraph is based on the fact that Jakarta has waterways that flow from the same source point and join again at the same end point. A multidigraph is a directed graph which is permitted to have multiple edges that share the same source and target nodes (Biswas et al., 2013). Figure 2. is a hypothetical multidigraph, where Edge 1 and Edge 2 depict two waterways originating from the same source (Node A) and flowing to the same point (Node B).

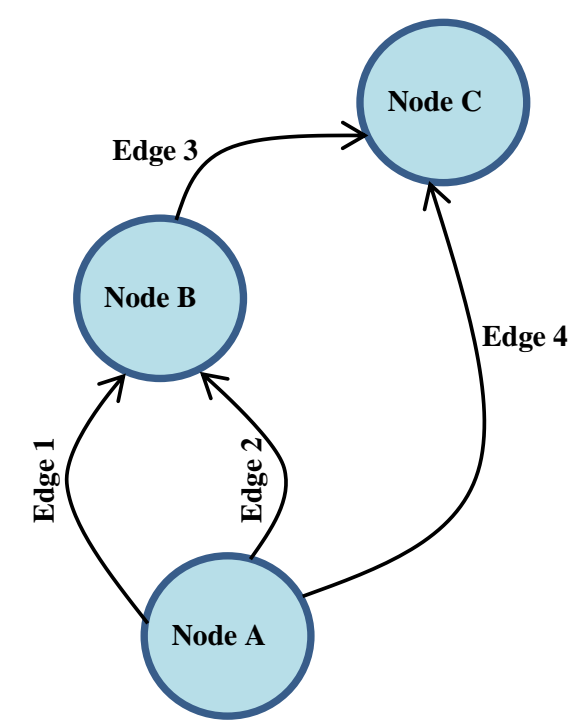

Figure 2. A hypothetical multidigraph

On successfully constructing the network, Eq. 5 and Eq. 6 were applied to compute the HIFVI and HIFVI (max) values for all 30 floodgates in the city of Jakarta. This activity was implemented using the mathematical functionalities provided by the NetworkX Python library. The computed data was organised in tabular form using the Pandas Python library and then stored in a PostGIS database so that it can be visualised cartographically using a geographical information system software such as QGIS. The results are presented and discussed in the following section.

\section{Results and discussions}


The results of the HIFVI and HIFVI (max) computed in the case study application are index values representing the degree to which each floodgate in the city of Jakarta is vulnerable to failure or damage caused by the impact of floodwaters. To facilitate comparative assessment of infrastructure vulnerability to flood hazards, the values obtained for HIFVI and $\mathrm{HIFVI}_{(\max )}$ were normalised to give dimensionless numbers from 0 to 1 as shown in Table 1 (Balica et al., 2012). In the normalised values, 1 indicates the highest vulnerability while 0 represents the lowest vulnerability. It is also important to note that computed indicators for susceptibility, exposure and resilience shown in Table 1 are the raw figures prior to scaling to dimensionless numbers from 1-10 as required for calculating

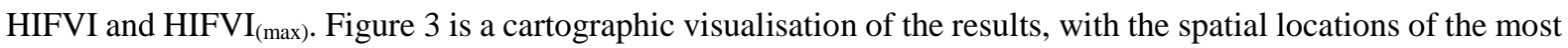
vulnerable infrastructure in the network highlighted in red colour. The results (see Table 1) show that "Pintu Air Sunter C" ranked as the most vulnerable floodgate, followed by "Pintu Air Ciliwung Lama" and "Pintu Air Kebon Baru" in that order. Such vulnerability ranking information can be useful in facilitating priority-based allocation of limited resources for flood preparedness and routine maintenance of the hydrological infrastructure.

Table 1: Computed vulnerability metrics for Jakarta's floodgates

\begin{tabular}{|c|c|c|c|c|c|c|c|}
\hline Floodgate & ID & $\begin{array}{l}\text { Susceptibility } \\
(\#)\end{array}$ & $\begin{array}{l}\text { Length of } \\
\text { waterways } \\
\text { flowing to } \\
\text { floodgate } \\
(\mathrm{km})\end{array}$ & $\begin{array}{l}\text { Total } \\
\text { exposure } \\
(\mathbf{k m})\end{array}$ & $\begin{array}{l}\text { Resilience } \\
\text { based on } \\
\text { redundancy } \\
\text { provided by } \\
\text { upstream } \\
\text { floodgate } \\
\text { (gates/km) }\end{array}$ & $\begin{array}{l}\text { HIFVI } \\
\text { (dimensionless) }\end{array}$ & $\begin{array}{l}\text { HIFVI(max) } \\
\text { (dimensionless) }\end{array}$ \\
\hline Pintu Air Sunter C & 27 & 1.000 & 190.490 & 144.301 & 0.014 & 1.0000 & 1.0000 \\
\hline Pintu Air Ciliwung Lama & 5 & 1.000 & 133.645 & 115.680 & 0.053 & 0.7715 & 0.8016 \\
\hline Pintu Air Kebon Baru & 17 & 1.000 & 122.592 & 108.226 & 0.000 & 0.7602 & 0.7499 \\
\hline Pintu Air Muara Angke & 20 & 0.500 & 429.371 & 215.771 & 0.428 & 0.5309 & 0.7475 \\
\hline Pintu Air Istiqlal & 10 & 0.333 & 160.466 & 133.039 & 0.127 & 0.2763 & 0.3070 \\
\hline Pintu Air Hailai & 8 & 0.500 & 169.774 & 139.295 & 0.775 & 0.2757 & 0.4824 \\
\hline Pintu Air Poglar & 23 & 0.333 & 259.248 & 116.041 & 0.000 & 0.2717 & 0.2678 \\
\hline Pintu Air Tangki & 29 & 0.500 & 164.020 & 136.593 & 0.937 & 0.2477 & 0.4731 \\
\hline Pintu Air Pasar Ikan & 21 & 0.250 & 307.387 & 206.455 & 0.499 & 0.2418 & 0.3574 \\
\hline Pintu Air Jembatan Merah & 11 & 0.250 & 163.090 & 135.663 & 0.100 & 0.2166 & 0.2347 \\
\hline Pintu Air Karet 2 & 16 & 0.500 & 150.296 & 85.201 & 0.393 & 0.2147 & 0.2949 \\
\hline Pintu Air Cengkareng Drain & 4 & 0.250 & 221.565 & 104.843 & 0.000 & 0.1841 & 0.1813 \\
\hline Pintu Air Honda & 9 & 0.167 & 191.084 & 143.963 & 0.013 & 0.1663 & 0.1659 \\
\hline Pintu Air Cakung Drainase & 3 & 0.333 & 164.232 & 64.095 & 0.000 & 0.1500 & 0.1477 \\
\hline Pintu Air Ancol & 2 & 0.200 & 176.824 & 141.414 & 0.515 & 0.1311 & 0.1957 \\
\hline Pintu Air Pekapuran & 22 & 0.200 & 170.121 & 139.700 & 0.638 & 0.1198 & 0.1933 \\
\hline Pintu Air Citra Land & 6 & 0.333 & 153.771 & 88.229 & 0.748 & 0.1181 & 0.2035 \\
\hline Pintu Air Pulogadung & 24 & 0.167 & 143.497 & 52.640 & 0.000 & 0.0616 & 0.0604 \\
\hline Pintu Air Kampung Gusti & 14 & 0.500 & 259.729 & 116.281 & 6.247 & 0.0563 & 0.4027 \\
\hline Pintu Air 8 & 1 & 0.125 & 151.231 & 55.749 & 0.255 & 0.0390 & 0.0479 \\
\hline Pintu Air Sogo & 26 & 0.500 & 36.238 & 15.640 & 0.534 & 0.0358 & 0.0538 \\
\hline
\end{tabular}




\begin{tabular}{|l|l|l|l|l|l|l|l|}
\hline Pintu Air Warung Pedok & 30 & 0.500 & 12.814 & 6.407 & 0.000 & 0.0225 & 0.0218 \\
\hline Pintu Air Manggarai & 18 & 0.333 & 21.792 & 9.700 & 0.189 & 0.0191 & 0.0220 \\
\hline Pintu Air Setia Budi & 25 & 0.333 & 19.697 & 8.517 & 0.149 & 0.0173 & 0.0193 \\
\hline Pintu Air Minangkabau & 19 & 0.500 & 15.936 & 7.962 & 0.641 & 0.0170 & 0.0272 \\
\hline Pintu Air Kalimati & 13 & 0.500 & 3.035 & 1.012 & 0.000 & 0.0035 & 0.0031 \\
\hline Pintu Air Duri & 7 & 0.333 & 3.092 & 1.174 & 0.000 & 0.0027 & 0.0023 \\
\hline Pintu Air Karet & 15 & 0.250 & 150.328 & 85.226 & 62.261 & 0.0023 & 0.1473 \\
\hline Pintu Air Sunter Utara & 28 & 0.250 & 0.917 & 0.229 & 0.000 & 0.0004 & 0.0000 \\
\hline Pintu Air Kali Cideng & 12 & 0.333 & 150.329 & 85.227 & 5524.270 & 0.0000 & 0.1966 \\
\hline
\end{tabular}




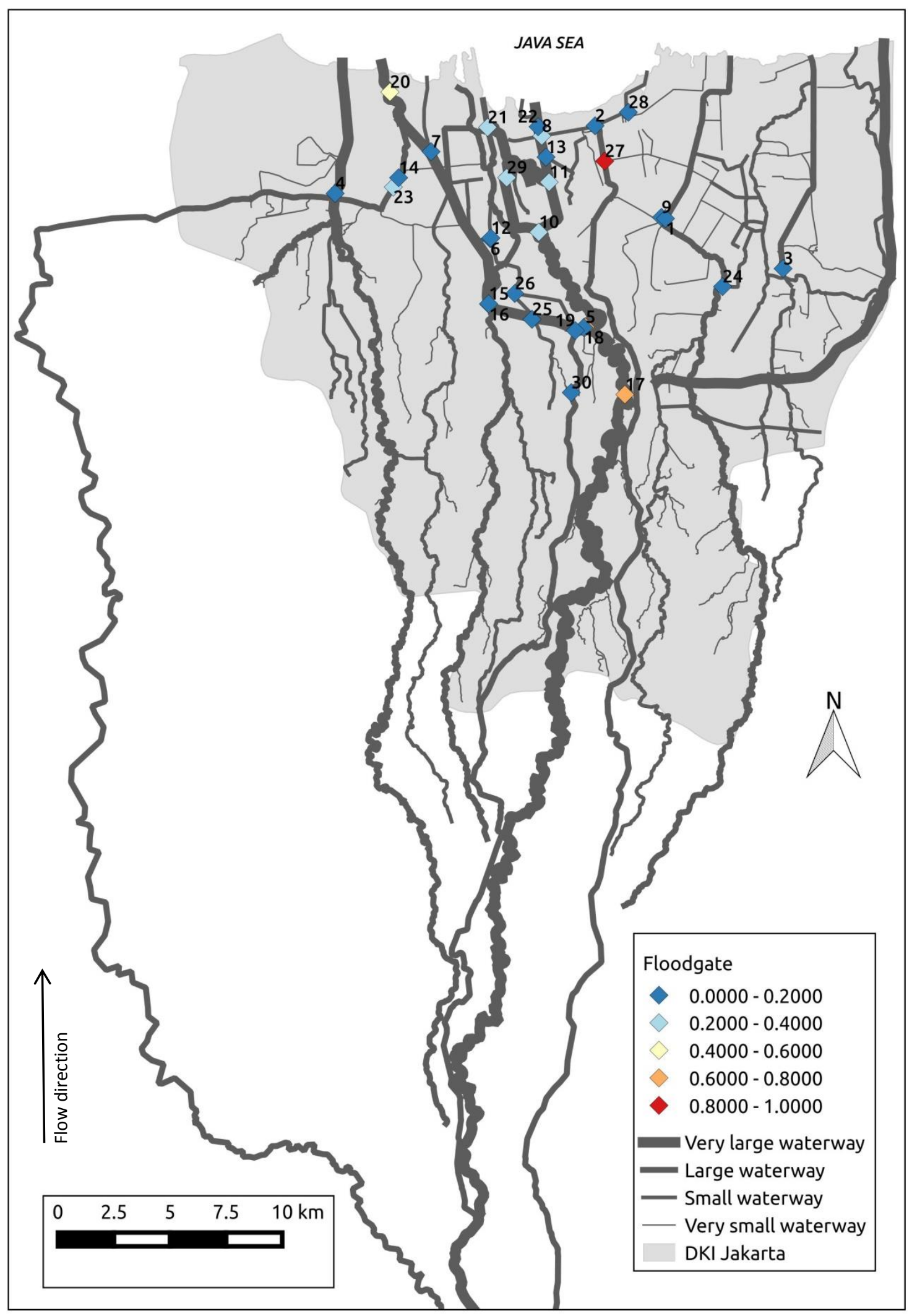

Figure 3. Jakarta's hydrological infrastructure network, showing locations of floodgates using their ID, with the most vulnerable floodgates (based on computed HIFVI) highlighted in red on a red-yellow-blue colour scale. 
In addition, Table 1 shows that the vulnerability of the top $10 \%$ of Jakarta's most vulnerable floodgates (i.e., "Pintu Air Sunter C", "Pintu Air Ciliwung Lama" and "Pintu Air Kebon Baru") can be mainly attributed to their high exposure to floodwaters, combined with high susceptibility. The high susceptibility of these three floodgates is due to the fact that each of them only have one gate unit compared to very low vulnerability ranking floodgates like "Pintu Air Sunter Utara", "Pintu Air Pulogadung", and "Pintu Air 8" which have 4, 6, and 8 gates units respectively. To minimise the vulnerability of these three floodgates (i.e., "Pintu Air Sunter C", "Pintu Air Ciliwung Lama" and "Pintu Air Kebon Baru"), limited resources can be prudently spent on increasing their capacities by installing additional gate units where possible. These results demonstrate the usefulness of the proposed vulnerability assessment approach in providing clues as to what actions can be taken to minimise infrastructure vulnerability. Undoubtedly, this outcome will be beneficial to coastal cities and external funding bodies who often require transparent and scientifically justified decisions on where limited resources allocated for flood control should be invested (Odeh, 2002).

Furthermore, the results show that "Pintu Air Kebon Baru" does not have any connected upstream floodgate, hence its resilience based on redundancy provided by connected upstream floodgates is 0 (see Table 1). To further minimise the vulnerability of "Pintu Air Kebon Baru", its resilience can be improved by installing one or more floodgates in upstream locations. Given the issue of aging and infrastructure fragility (Turpin et al., 2013), this approach of identifying potential locations and installing additional floodgates to control flooding ensures that no singular infrastructure component (e.g. "Pintu Air Kebon Baru") is excessively exposed to floodwater damage. By applying this approach to other floodgates in the system, potential locations for new installations can be identified network-wide. This demonstrates the usefulness of the proposed solution in highlighting possible locations where additional infrastructure may be required.

Moreover, when the computed values for HIFVI and HIFVI(max) are compared (see Table 1 and Figure 4), the results show a strong correlation. This implies that even in worse-case scenario when all upstream floodgates are opened so that water flows unobstructed to create maximum impact on downstream floodgates, the vulnerability of majority of the floodgates in Jakarta do not change significantly. 


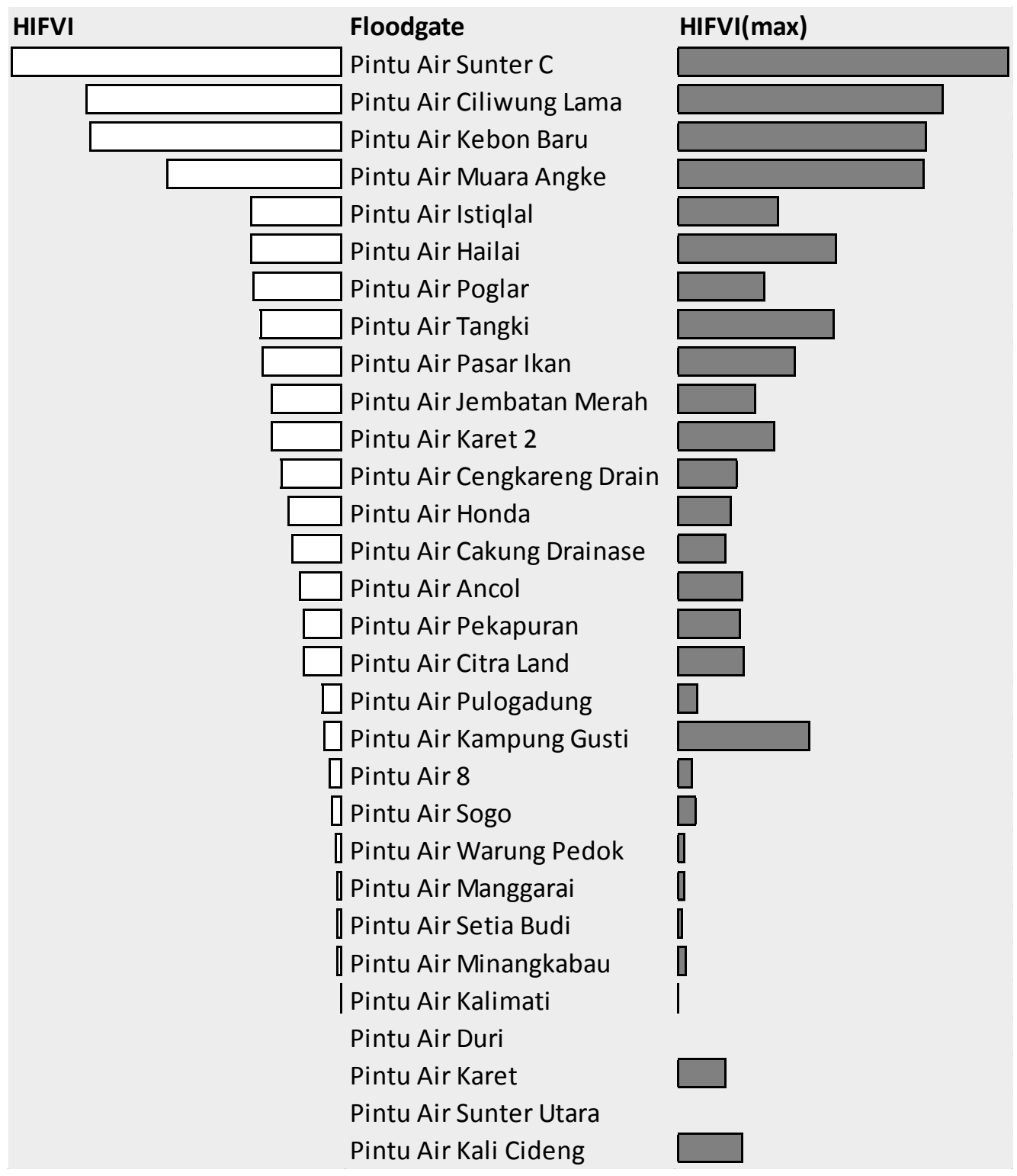

Figure 4. Comparing ranked HIFVI values with $\mathrm{HIFVI}_{(\max )}$ values for the same floodgates in the city of Jakarta

The results show that the current network configuration in terms of topology and connectivity of Jakarta's floodgates does not significantly contribute to improve their resilience and minimise vulnerability. However, as shown in Table 1 and Figure 4, there are a few floodgates in the network (e.g., "Pintu Air Kali Cideng", "Pintu Air Karet" and "Pintu Air Kampung Gusti") whose vulnerability increases significantly when the upstream floodgates connected to them are opened and water flows unobstructed to create maximum impact. The vulnerability of these floodgates (i.e., "Pintu Air Kali Cideng”, "Pintu Air Karet” and "Pintu Air Kampung Gusti”) therefore depend strongly on the resilience provided by other connected upstream floodgates. Hence, when most upstream floodgates are kept opened, it is important to monitor the aforementioned floodgates to avoid excessive exposure to the damaging impacts of floodwaters. 


\subsection{Social-economic implications of infrastructure vulnerability}

Urban infrastructure, including those used for flood control, are fundamental to the safety, productivity and dayto-day operation of modern society (Ogie et al., 2017c). During intense rainfall events, flood control infrastructure such as floodgates (or sluice gates), dams, embankments, and flood barriers play crucial roles in keeping people and communities safe from urban floods. In Jakarta, the failure of hydraulic components (e.g., pumps, floodgates, etc.) within the hydrological infrastructure network, often result in severe flooding events that have devastating impact on the people, property, economy, and environment (World Bank, 2010). The loss associated with floods in Jakarta is over USD 400 million per year (World Bank, 2010). It is therefore pertinent that when interpreting the results of infrastructure vulnerability assessments, the social and economic implications of the failure of such infrastructure should be considered. For example, a floodgate may rank as having low vulnerability to flood damage, but its failure may result in flooding that has severe economic and social impact on affected communities. Narayan et al. (2012) used the Source-Pathway-Receptor (SPR) concept to describe how natural hazards such as floods flow from a source, through different pathways to potentially cause undesirable impact on receptors. These receptors, described here and elsewhere as elements at risk, include people, households, residential property, companies, critical infrastructure, etc. (Merz et al., 2010; Meyer et al., 2009; Wijayanti et al., 2017). Principally, identifying elements at risk enables the prioritisation of limited resources toward minimising the failure of flood control infrastructure that protect areas with the highest density of people, urban property, and economic activities (Szlafsztein and Sterr, 2007). This will require an understanding of what is at risk and the socio-economic impact associated with the materialisation of such risk so that appropriate actions can be taken to minimise flood damage in areas of high risk exposure.

However, the task of accurately identifying the socio-economic impact of flood damage that may arise from the failure of a flood control infrastructure requires significant amount of data. Typically, the socio-economic impact of flood damage is estimated based on damage functions, which require data about elements at risk, in addition to flood characteristics such as depth, duration, spatial extent, velocity, and contamination associated with floods (Merz et al., 2010; Wijayanti et al., 2017). Other data inputs that may be relevant for such analysis include digital elevation model (DEM) and land-use information (Dewan et al., 2007). Unfortunately, comprehensive and accurate records of these data are often not available in developing nations. In a recent study aimed at estimating river flood damage in Jakarta- a coastal megacity situated in a developing nation, the lack of data about flood 
characteristics was identified as a major limitation to the scope and depth of the analysis (Wijayanti et al., 2017). The present study also uses Jakarta as its study area and faces similar drawback due to lack of comprehensive and accurate data.

Nevertheless, using limited available data, this study presents results (Figures 5, 6, and 7) that show cartographically, the vulnerability and locations of Jakarta's floodgates along with the density of human population living in surrounding neighbourhoods across the city. Recall that floodgates provide flood protection to neighbouring communities during intense rainfall events. Neighbourhoods, which are located upstream or downstream of a floodgate, are considered to be directly at risk of flood hazards when the floodgate fails. For example, if a floodgate fails to close during an intense rainfall event, water may flow unobstructed to inundate neighbouring communities located downstream. If on the other hand, it was the opening mechanism of the floodgate that failed, neighbouring communities located upstream may become inundated, depending on the flood characteristics. Ultimately, the decision on whether to open or close a floodgate depends on risk exposure in upstream versus downstream locations, and the failure of such floodgate will, no doubt, undermine the ability to protect the neighbourhoods served by the floodgate.

There are currently 267 neighbourhoods or administrative villages (popularly known as "kelurahan") in Jakarta (Eilander et al., 2016). The average size of a kelurahan is $2.48 \mathrm{~km} 2$ and the average human population is 49,709 (Jakarta Open Data, 2013). For each kelurahan, we considered the population density, i.e., the number of human inhabitants per square kilometre, for the entire population (shown in Figure 5) as well as for vulnerable classes of the population, including children between 0-4 years (shown in Figure 6), females, and the elderly aged 70 and above (shown in Figure 7). According to Dewan (2013), females are considered to be part of the population that are more vulnerable to disasters, but we did not show a specific map for this class because the male-to-female ratio in Jakarta is 1.03 , meaning that the map for the female class is almost the same as that for the entire population (Dewan, 2013).

The results shown in Figures 5, 6, and 7 indicate that except for the elderly class aged 70 and above, 'Pintu Air Sunter C' with floodgate ID 27 provides flood protection to upstream neighbourhoods with relatively higher density of people, including children and females. Considering that "Pintu Air Sunter C" ranked as the most vulnerable floodgate in the network, it is crucial that significant effort (e.g., maintenance activities) be put in place 
to prevent its failure during flooding events. It is observed from Figures 5, 6, and 7 that neighbourhoods within Jakarta North West (highlighted in Figure 7 with a broken-line polygon) generally have high population density across all classes of the population compared to other parts of the city. It is therefore crucial that high vulnerability floodgates such as those with IDs 29, 2, 20, 23, and 10 which directly provide flood protection to the highlighted neighbourhoods be prioritised for maintenance. This is particularly important as Figure 7 specifically shows that Jakarta's elderly population (70 years and above) are concentrated in this region. Similarly, floodgates with IDs 2 and 28 have relatively low vulnerability due to the redundancy and therefore resilience each provide to one another. However, these two floodgates must be prevented from failing because of the crucial service of flood protection they provide to downstream neighbourhoods with high population density across all classes of the population. 


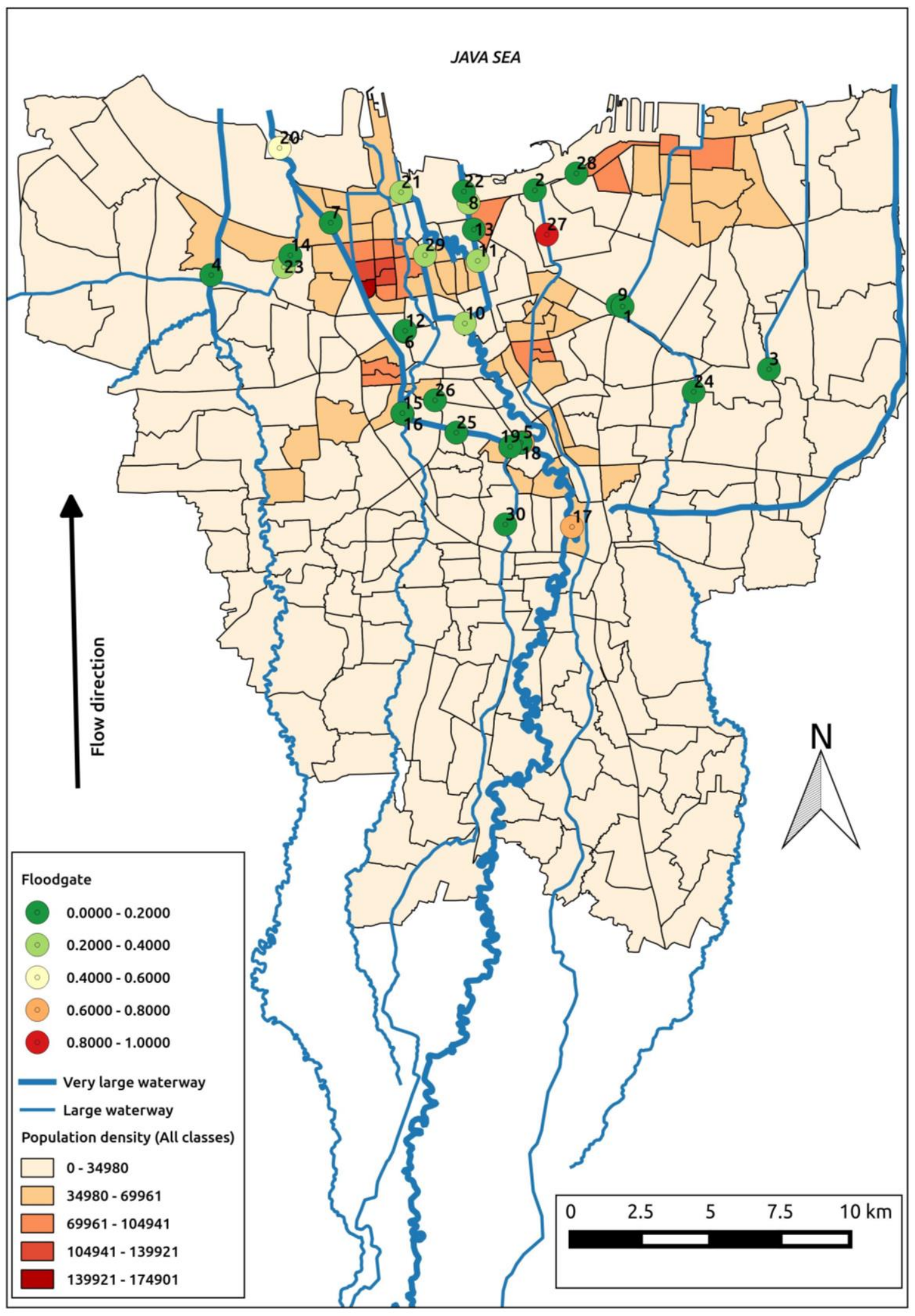

Figure 5. Map showing vulnerable locations of Jakarta's floodgates along with the population density in surrounding neighbourhoods across the city 


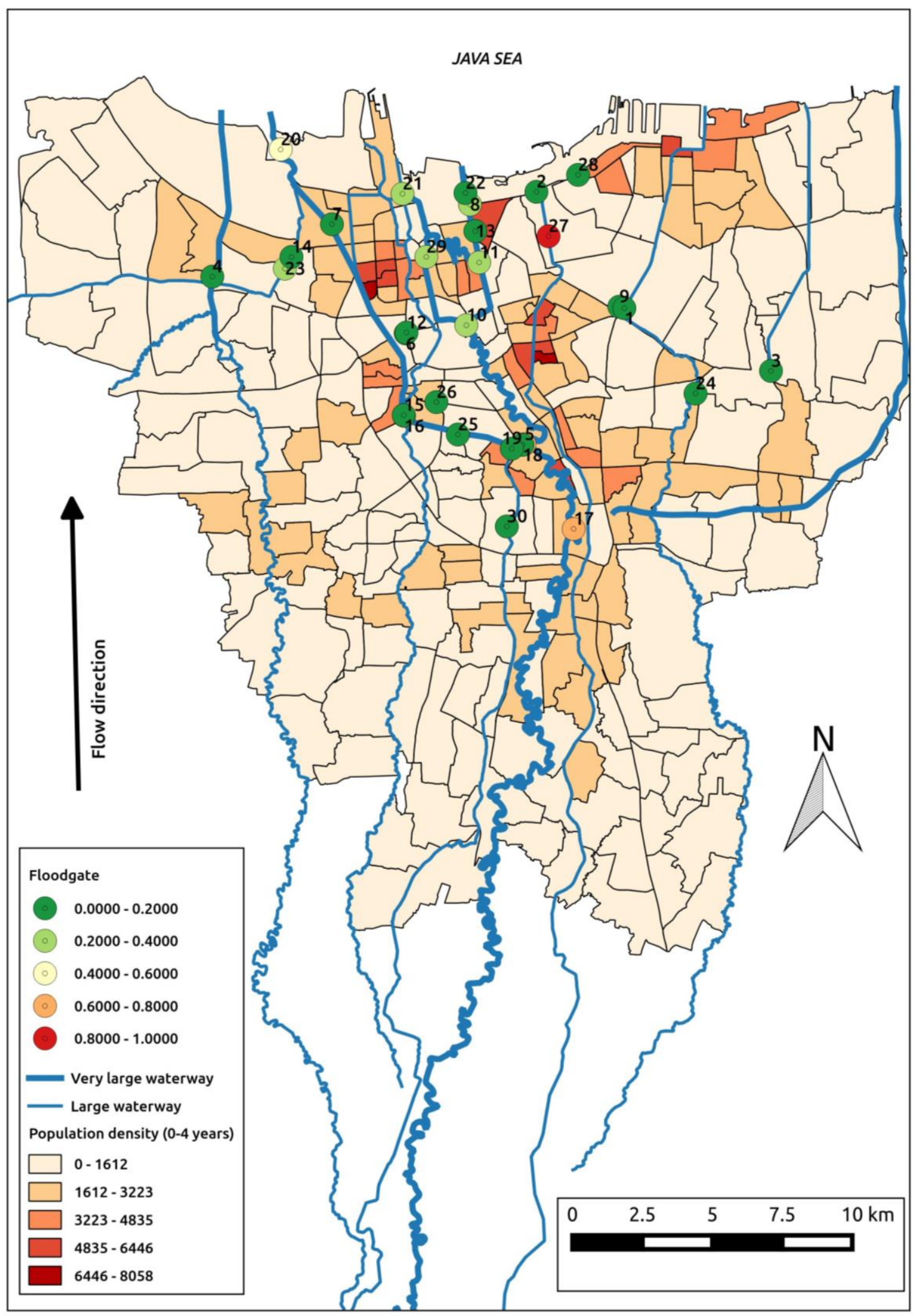

Figure 6. Map showing vulnerable locations of Jakarta's floodgates along with the population density of children (0-4 years) in surrounding neighbourhoods across the city 


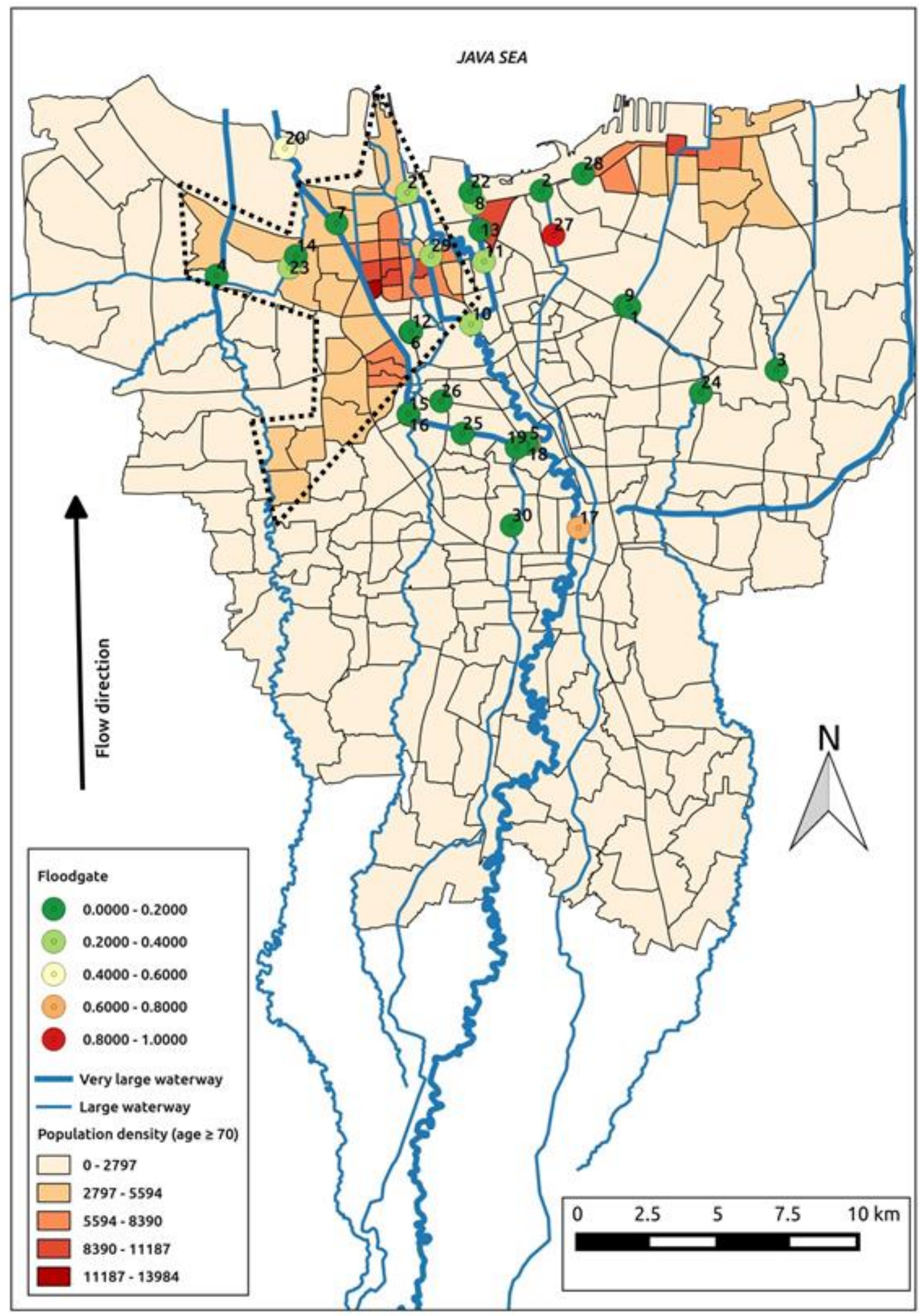

Figure 7. Map showing vulnerable locations of Jakarta's floodgates along with the population density of the elderly (70 years and above) in surrounding neighbourhoods across the city 
Figure 6 shows that there are high population densities for children (0-4 years) across many neighbourhoods in Jakarta. A major concern for this vulnerable class of the population is that many of these neighbourhoods with high population density of children (0-4 years) are located in slum areas next to very large waterways. In Jakarta and many other coastal megacities situated in developing nations, there are millions of urban poor, most of whom can only afford to reside in slums next to the river, making them very vulnerable to flood hazards (Dewan, 2013). These socially disadvantaged citizens residing in informal settlements are often considered by the government as "illegal elements of society" and are excluded from formal planning and preparation for flood hazards (Dewan, 2013). These results (see Figure 6) have shown that there is high density of children (0-4 years) living in slum areas next to major rivers. In the context of Jakarta, it is therefore crucial that the floodgate that ranked as the third most vulnerable, i.e., "Pintu Air Kebon Baru" with ID 17, be properly maintained and operated to provide flood protection to vulnerable children and their families crowded in downstream neighbourhoods.

Unfortunately, the way flood control infrastructure such as floodgates are being managed and operated in developing nations raise questions that bother on fairness, equity and justice. This is particularly important for coastal megacities where most parts of the cities are densely occupied with people, buildings, urban infrastructure, and economic activities, so much so that there are only few reservoirs and spaces to channel flood water ( $\mathrm{Li}$, 2003). This means some communities may have to be allowed to flood in order to safeguard other areas considered to be of higher priority based on socio-economic profile. It is a complex situation when decisions have to be made as to whether or not a floodgate should be managed to prioritise neighbourhoods occupied by prosperous groups over a larger population of the urban poor crowded in low-income neighbourhoods. Sometimes, it comes down to a decision of whether or not to prioritise human lives over urban property and economic activities worth millions of dollars. In 2013, the presidential palace in Jakarta was flooded because "Pintu Air Manggarai”, with floodgate ID 18 was opened to lessen inundation in other parts of the city (Sedlar, 2016). With conflicting interest on what areas should be prioritised for flood protection, it is not uncommon for neighbourhoods to disagree and fight over how flood control infrastructure should be managed during flooding events (Caljouw et al., 2005). Caljouw et al. (2005) reports a flooding event in Jakarta where soldiers were brought in and given orders to shoot any disgruntled resident who tries to interfere with the management of a floodgate (Caljouw et al., 2005). This situation reinforces the importance of transparent and scientifically justified approaches, as proposed in this study, to improve management decisions related to flood control infrastructure in developing nations. 


\section{Conclusions}

This study has proposed a new flood vulnerability index that can be applied to measure and rank the vulnerability of hydrological infrastructure assets (e.g., floodgates or sluice gates, dams, embankments, flood barriers, etc.) in coastal cities. The proposed methodology relies on topological/connectivity analysis of a graph model of the hydrological infrastructure network. In this approach, vulnerability is computed using the concepts of exposure, sensitivity and resilience. An application of the proposed technique to Jakarta's floodgates produced index values that highlights the most vulnerable floodgates in the network. Two different conditions of flood vulnerability were considered- the case in which all connected upstream floodgates were closed (i.e., HIFVI) and the case in which all connected upstream floodgates were opened so that floodwaters create maximum impact on downstream floodgates (i.e., $\left.\operatorname{HIFVI}_{(\max )}\right)$. Generally, there was a strong correlation in the results obtained in both cases except for a few floodgates that were observed to have vulnerability that depends mainly on the resilience provided by connected upstream floodgates. It is envisaged that the results will facilitate transparent and effective allocation of limited resources for maintenance and upgrades to the flood control infrastructure within coastal cities situated in developing nations.

More importantly, the results show that the proposed vulnerability assessment technique can be useful in providing clues as to what actions can be taken to minimise infrastructure vulnerability. The technique was also found to be useful in identifying potential locations where additional infrastructure may be required to improve resilience to flooding. No doubt, the vulnerability assessment technique proposed in this study will enable coastal cities in developing nations plan for more resilient hydrological infrastructure and to improve the outcome of structural measures to flood mitigation. The application of the proposed technique can be extended to a wide range of hydrological infrastructure used for flood control in coastal cities, including sluice gates, dams, flood walls, embankments, dykes, and other flood barriers.

It is important to note that the accuracy and reliability of the results presented are limited by the data available for this study. One limitation of this study is the absence of additional data about the hydrological infrastructure and channel conditions to help improve the quality and reliability of the result. Hence, future study will seek to improve the accuracy of the technique by introducing additional data such as the age, maintenance history, and failure history of hydrological infrastructure, as well as the actual force of impact from floodwaters on the infrastructure. In addition, the present study only considers unidirectional flow along a network of rivers, streams, 
canals etc. In other words, it focuses on river or fluvial flooding because this is the most common type of flooding in riverine areas. Another reason for focusing on fluvial flooding is that hydrological interaction with flood control infrastructure occur mainly through the river network. Nevertheless, pluvial floods and coastal floods also occur occasionally and are associated with extreme rainfall runoff and sea level rise respectively. In future studies, the proposed methodology can be extended to consider multidirectional flow scenarios involving all types of floods (e.g. fluvial, coastal and pluvial flooding), but this will further introduce complexity into the methodology. This aspect of conveying complex information is where the graphical system level model proposed by Narayan et al. (2012) for assessing large coastal flood systems and topological relationships between individual elements is considered advantageous over approaches based on topographic maps. Nonetheless, the proposed methodology remains novel for comparatively assessing the vulnerability of hydrological infrastructure (e.g., floodgate, dams, flood barriers, etc.) used for flood control in coastal cities.

Furthermore, the study discussed the socio-economic implications of infrastructure vulnerability, but relied on limited available data about population density. If more data required for assessing potential impacts of flood hazards become available in the future, this limitation can be addressed by extending the study to consider other factors, including flood characteristics (e.g., depth, duration, spatial extent, velocity, and contamination associated with floods), land use information, locations of major economic activities (i.e., industries, tourist sites, fisheries, agriculture, etc.), lifelines or information about critical infrastructure (e.g., electricity network, gas supply network, water distribution network, airports, road network and evacuation routes, hospitals, etc.). A growing body of knowledge (see for example, Kawamura et al., 2014; Montoya 2003; Ogie et al., 2017d; Poblet et al., 2014) suggests that mobile technology has huge potentials to support the information needs of modern disaster management initiatives. Apparently, mobile technology can facilitate an inclusive and participatory approach of data collection and decision making, involving local knowledge from citizens and representatives of affected neighbourhoods, as required to capture a fair and comprehensive list of what is valuable and what constitutes elements at risk across different communities. Such co-created detailed information about elements at risks, currently unavailable in many developing coastal megacities, is crucial for making objective, balanced and fair decisions on areas that should be prioritised for flood protection.

\section{References}

Adger, W.N. (1999). Social vulnerability to climate change and extremes in coastal Vietnam. World development, 27(2), 249-269. 
Al-Sabhan, W., Mulligan, M. \& Blackburn, G.A. (2003). A real-time hydrological model for flood prediction using GIS and the WWW. Computers, Environment and Urban Systems, 27(1), 9-32.

Balica, S.F., Wright, N.G. \& van der Meulen, F. (2012). A flood vulnerability index for coastal cities and its use in assessing climate change impacts. Natural Hazards 64,73-105.

Barr, S., Holderness, T., Alderson, D., et al. (2012). An open source relational database schema and system for the analysis of large scale spatial interdependent infrastructure networks. In: Proceedings of the 4th Open Source GIS Conference, Nottingham, AK. Available http://eprint.ncl.ac.uk/pub_details2.aspx?pub_id1/4196369.

Biswas, S. S., Alam, B., \& Doja, M. N. (2013). Real time multigraphs for communication networks: An intuitionistic fuzzy mathematical model. Journal of Computer Science, 9(7), 847-855.

Brecht, H., Dasgupta, S., Laplante, B., Murray, S., \& Wheeler, D. (2012). Sea-level rise and storm surges: High stakes for a small number of developing countries. The Journal of Environment \& Development, 21(1), 120138.

Brooks, N. (2003). Vulnerability, risk and adaptation: A conceptual framework. Tyndall Centre for Climate Change Research, University of East Anglia, Norwic, Working Paper, 38, 1-16.

Bunn, A. G., Urban, D. L., \& Keitt, T. H. (2000). Landscape connectivity: a conservation application of graph theory. Journal of environmental management, 59(4), 265-278.

Caljouw, M., Nas, P. J., \& Pratiwo, M. R. (2005). Flooding in Jakarta: Towards a blue city with improved water management. Bijdragen tot de taal-, land-en volkenkunde/Journal of the Humanities and Social Sciences of Southeast Asia, 161(4), 454-484.

Chakraborty, J., \& Armstrong, M. P. (1995). Using geographic plume analysis to assess community vulnerability to hazardous accidents. Computers, Environment and Urban Systems, 19(5-6), 341-356.

Chang, S. E., \& Shinozuka, M. (2004). Measuring improvements in the disaster resilience of communities. Earthquake Spectra, 20(3), 739-755.

Ciurean, R. L., Schröter, D., \& Glade, T. (2013). Conceptual frameworks of vulnerability assessments for natural disasters reduction. In Approaches to disaster management-Examining the implications of hazards, emergencies and disasters. InTech.

Cutter, S. L., Barnes, L., Berry, M., Burton, C., Evans, E., Tate, E., \& Webb, J. (2008). A place-based model for understanding community resilience to natural disasters. Global environmental change, 18(4), 598-606.

Cutter, S. L., Emrich, C. T., Webb, J. J., \& Morath, D. (2009). Social vulnerability to climate variability hazards: A review of the literature. Final Report to Oxfam America, 5, 1-44.

Dawson, R. J., Speight, L., Hall, J. W., Djordjevic, S., Savic, D., \& Leandro, J. (2008). Attribution of flood risk in urban areas. Journal of Hydroinformatics, 10(4), 275-288.

Dewan, A. (2013). Floods in a megacity: geospatial techniques in assessing hazards, risk and vulnerability. Dordrecht: Springer.

Dewan, A. M., Islam, M. M., Kumamoto, T., \& Nishigaki, M. (2007). Evaluating flood hazard for land-use planning in Greater Dhaka of Bangladesh using remote sensing and GIS techniques. Water resources management, 21(9), 1601-1612.

Dewan, A. M., \& Yamaguchi, Y. (2008). Effect of land cover changes on flooding: example from Greater Dhaka of Bangladesh. International Journal of Geoinformatics, 4(1), 11-20.

Ding, Y., \& Wang, S. S. (2012). Optimal control of flood diversion in watershed using nonlinear optimization. Advances in water resources, 44, 30-48.

D'Lima, M., \& Medda, F. (2015). A new measure of resilience: An application to the London Underground. Transportation Research Part A: Policy and Practice, 81, 35-46.

Dunn, S., Fu, G., Wilkinson, S., \& Dawson, R. (2013, October). Network theory for infrastructure systems modelling. In Proceedings of the Institution of Civil Engineers-Engineering Sustainability, 166(5), $281-292$.

Ezell, B. C. (2007). Infrastructure Vulnerability Assessment Model (I- VAM). Risk Analysis, 27(3), 571-583.

Gallopín, G. C. (2006). Linkages between vulnerability, resilience, and adaptive capacity. Global environmental change, 16(3), 293-303.

Green, C. (2004). The evaluation of vulnerability to flooding. Disaster Prevention and Management: An International Journal, 13(4), 323-329.

Grega, S.J., Stender, J. \& Fulsaas, L. (2010). Dams \& Civil Structures: A Challenging Gate Repair at Cowlitz Falls. Hydro review, 29(5), [cited 2017 February 25]. Available from: http://www.hydroworld.com/articles/hr/print/volume-29/issue-5/articles/dams--civil-structures.html

Hallegatte, S., Green, C., Nicholls, R. J., \& Corfee-Morlot, J. (2013). Future flood losses in major coastal cities. Nature climate change, 3(9), 802-806.

Hall, J. W., Meadowcroft, I. C., Sayers, P. B., \& Bramley, M. E. (2003). Integrated flood risk management in England and Wales. Natural Hazards Review, 4(3), 126-135.

Hardoy, J., \& Pandiella, G. (2009). Urban poverty and vulnerability to climate change in Latin America. Environment and Urbanization, 21(1), 203-224. 
Holmgren, A. J. (2006). Using graph models to analyze the vulnerability of electric power networks. Risk analysis, 26(4), 955-969.

Hartono, D. M., Novita, E., Gusniani, I., \& Oriza, I. I. D. (2010). The role of water supply and sanitation during floods: Case study of flood disaster in five regions of jakarta. International Journal of Technology, 1(1), 2937.

Huang, D., Zhang, R., Huo, Z., Mao, F., Youhao, E., \& Zheng, W. (2012). An assessment of multidimensional flood vulnerability at the provincial scale in China based on the DEA method. Natural hazards, 64(2), 15751586.

Hung, N. Q., Babel, M. S., Weesakul, S., \& Tripathi, N. K. (2009). An artificial neural network model for rainfall forecasting in Bangkok, Thailand. Hydrology and Earth System Sciences, 13(8), 1413-1425.

Hufschmidt, G. (2011). A comparative analysis of several vulnerability concepts. Natural hazards, 58(2), 621643.

Jenelius, E., \& Mattsson, L. G. (2015). Road network vulnerability analysis: Conceptualization, implementation and application. Computers, environment and urban systems, 49, 136-147.

Johnston, A., Slovinsky, P., \& Yates, K. L. (2014). Assessing the vulnerability of coastal infrastructure to sea level rise using multi-criteria analysis in Scarborough, Maine (USA). Ocean \& coastal management, 95, 176-188.

Kawamura, Y., Dewan, A. M., Veenendaal, B., Hayashi, M., Shibuya, T., Kitahara, I., ... \& Ishii, K. (2014). Using GIS to develop a mobile communications network for disaster-damaged areas. International Journal of Digital Earth, 7(4), 279-293.

Ke, Q. (2014). Flood risk analysis for metropolitan areas-a case study for Shanghai. TU Delft, Delft University of Technology.

Khan, S. (2012). Vulnerability assessments and their planning implications: a case study of the Hutt Valley, New Zealand. Natural Hazards, 64(2), 1587-1607.

Lall, S. V., \& Deichmann, U. (2010). Density and disasters: economics of urban hazard risk. The World Bank Research Observer, 27(1), 74-105.

Li, H. (2003). Management of coastal mega-cities - a new challenge in the 21st century. Marine Policy, 27(4), 333-337.

Masuya, A., Dewan, A., \& Corner, R. J. (2015). Population evacuation: evaluating spatial distribution of flood shelters and vulnerable residential units in Dhaka with geographic information systems. Natural Hazards, 78(3), 1859-1882.

Merz, B., Kreibich, H., Schwarze, R., \& Thieken, A. (2010). Review article" Assessment of economic flood damage". Natural Hazards and Earth System Sciences, 10(8), 1697-1724.

Meyer, Volker, Dagmar Haase, and Sebastian Scheuer. "Flood risk assessment in European river basins-concept, methods, and challenges exemplified at the Mulde river." Integrated Environmental Assessment and Management 5.1 (2009), 17-26.

Montoya, L. (2003). Geo-data acquisition through mobile GIS and digital video: an urban disaster management perspective. Environmental Modelling \& Software, 18(10), pp.869-876.

Mulyasari, F., Shaw, R., \& Takeuchi, Y. (2011). Chapter 12 Urban Flood Risk Communication for Cities. In Climate and disaster resilience in cities (pp. 225-259). Emerald Group Publishing Limited.

Narayan, S., Hanson, S., Nicholls, R. J., Clarke, D., Willems, P., Ntegeka, V., \& Monbaliu, J. (2012). A holistic model for coastal flooding using system diagrams and the Source-Pathway-Receptor (SPR) concept. Natural Hazards and Earth System Science, 12(5), 1431-1439.

Neumayer, S., Zussman, G., Cohen, R., \& Modiano, E. (2011). Assessing the vulnerability of the fiber infrastructure to disasters. IEEE/ACM Transactions on Networking (TON), 19(6), 1610-1623.

Odeh, D. J. (2002). Natural hazards vulnerability assessment for statewide mitigation planning in Rhode Island. Natural Hazards Review, 3(4), 177-187.

Ogie, R., Holderness, T., Dunbar, M., \& Turpin, E. (2017a). Spatio-topological network analysis of hydrological infrastructure as a decision support tool for flood mitigation in coastal mega-cities. Environment and Planning B: Urban Analytics and City Science, 44(4), 718-739.

Ogie, R. I., Dunn, S., Holderness, T., \& Turpin, E. (2017b). Assessing the vulnerability of pumping stations to trash blockage in coastal mega-cities of developing nations. Sustainable Cities and Society, 28, 53-66.

Ogie, R.I., Perez, P. \& Dignum, V. (2017c). Smart infrastructure: an emerging frontier for multidisciplinary research. Proceedings of the Institution of Civil Engineers-Smart Infrastructure and Construction, 170(1), 8-16.

Ogie, R.I., Perez, P., Win, K.T. and Michael, K., 2017d. Managing hydrological infrastructure assets for improved flood control in coastal mega-cities of developing nations. Urban Climate. https://doi.org/10.1016/j.uclim.2017.09.002. 
Poblet, M., García-Cuesta, E. and Casanovas, P., 2014. Crowdsourcing tools for disaster management: A review of platforms and methods. In AI Approaches to the Complexity of Legal Systems (pp. 261-274). Springer, Berlin, Heidelberg.

Sadoff, C., Harshadeep, N. R., Blackmore, D., Wu, X., O'Donnell, A., Jeuland, M., ... \& Whittington, D. (2013). Ten fundamental questions for water resources development in the Ganges: myths and realities. Water Policy, 15(S1), 147-164.

Sedlar, F. (2016). Inundated Infrastructure: Jakarta's Failing Hydraulic Infrastructure. Michigan Journal of Sustainability, 4; DOI: http://dx.doi.org/10.3998/mjs.12333712.0004.004.

Sims, J. (2013). The No-Nonsense Guide to Flood Safety. Lulu Books \& Beyond the Spectrum Books

Stalenberg, B., \& Vrijling, H. A. N. (2009). The battle of Tokyo and Dhaka against floods. Built Environment, 35(4), 471-491.

Szlafsztein, C., \& Sterr, H. (2007). A GIS-based vulnerability assessment of coastal natural hazards, state of Pará, Brazil. Journal of Coastal Conservation, 11(1), 53-66.

Taylor, M. A., Sekhar, S. V., \& D'Este, G. M. (2006). Application of accessibility based methods for vulnerability analysis of strategic road networks. Networks and Spatial Economics, 6(3-4), 267-291.

Thakur, P. K., Maiti, S., Kingma, N. C., Prasad, V. H., Aggarwal, S. P., \& Bhardwaj, A. (2012). Estimation of structural vulnerability for flooding using geospatial tools in the rural area of Orissa, India. Natural hazards, 61(2), 501-520.

Tingsanchali, T. (2012). Urban flood disaster management. Procedia engineering 32, 25-37.

Tonmoy, F. N., \& El-Zein, A. (2013, September). Vulnerability of infrastructure to sea level rise: a combined outranking and system-dynamics approach. In 22nd conference on European Safety and reliability (ESREL2013).

Turpin, É., Bobbette, A.W. \& Miller, M. (2013). Jakarta: Architecture+ Adaptation. Universitas Indonesia Press, Indonesia.

Uitto, J. I. (1998). The geography of disaster vulnerability in megacities: a theoretical framework. Applied geography, 18(1), 7-16.

Venkittaraman, A., \& Banerjee, S. (2014). Enhancing resilience of highway bridges through seismic retrofit. Earthquake Engineering \& Structural Dynamics, 43(8), 1173-1191.

Wei, Y. M., Wang, K., Wang, Z. H., \& Tatano, H. (2015). Vulnerability of infrastructure to natural hazards and climate change in China, Natural Hazards, 75, 107-110.

Wijayanti, P., Zhu, X., Hellegers, P., Budiyono, Y., \& van Ierland, E. C. (2017). Estimation of river flood damages in Jakarta, Indonesia. Natural hazards, 86(3), 1059-1079.

Wilkinson, S. M., Dunn, S., \& Ma, S. (2012). The vulnerability of the European air traffic network to spatial hazards. Natural hazards, 60(3), 1027-1036.

World Bank. (2010). Jakarta: urban challenges in a changing climate, A Mayors' task force on climate change, disaster risk, and the urban poor. The World Bank Indonesia, Jakarta.

[dataset] Jakarta Open Data (2013) http://data.jakarta.go.id/dataset/5b016474.../DKI-USIA2013.xls 